Supporting Information

\title{
Hybrid Amyloid Membranes for Continuous
}

\section{Flow Catalysis}

Sreenath Bolisetty ${ }^{1}$, Mario Arcari ${ }^{l}$, Jozef Adamcik ${ }^{1}$ \& Raffaele Mezzenga ${ }^{1, *}$

${ }^{1}$ ETH Zurich, Department of Health Sciences and Technology, Schmelzbergstrasse 9, 8092

Zurich, Switzerland.

*raffaele.mezzenga@hest.ethz.ch 


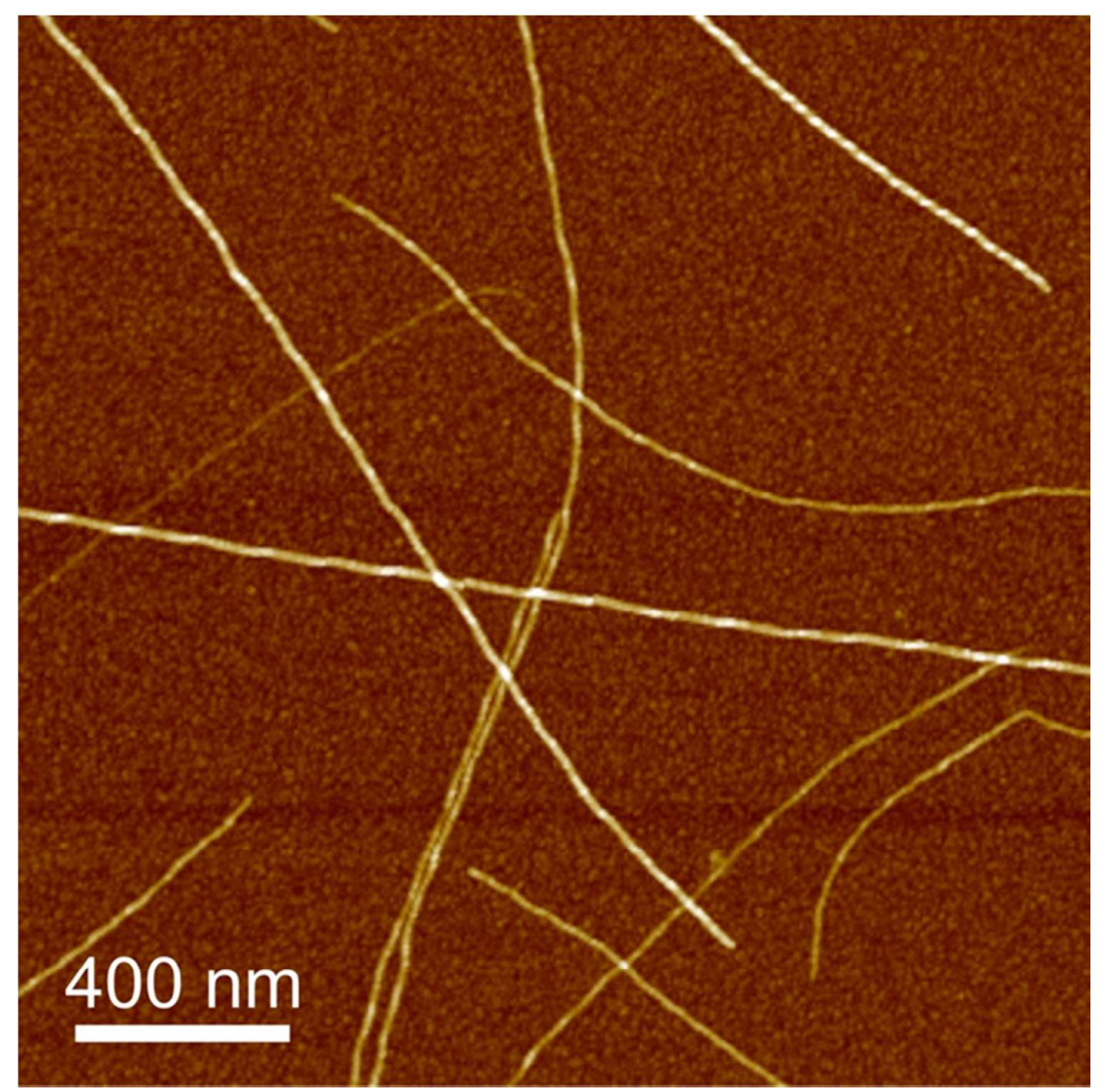

Figure S1. Atomic force microscope image of the $\beta$-lactoglobulin amyloid fibrils. 

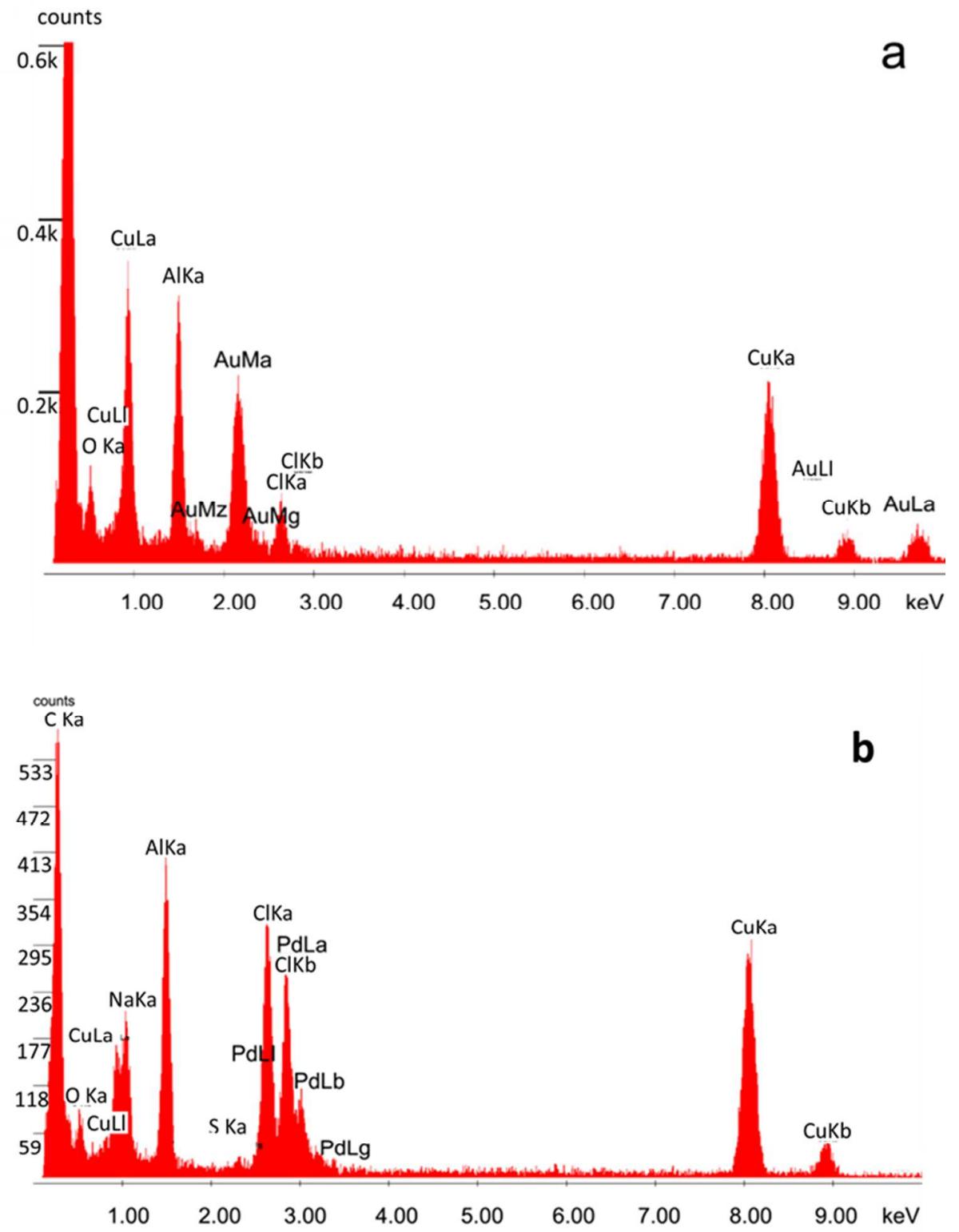

Figure S2. Energy dispersive X-ray spectroscopy of: a) gold, b) palladium nanoparticles decorating the surface of $\beta$-lactoglobulin fibrils, as measured on the carbon-coated copper grids. 


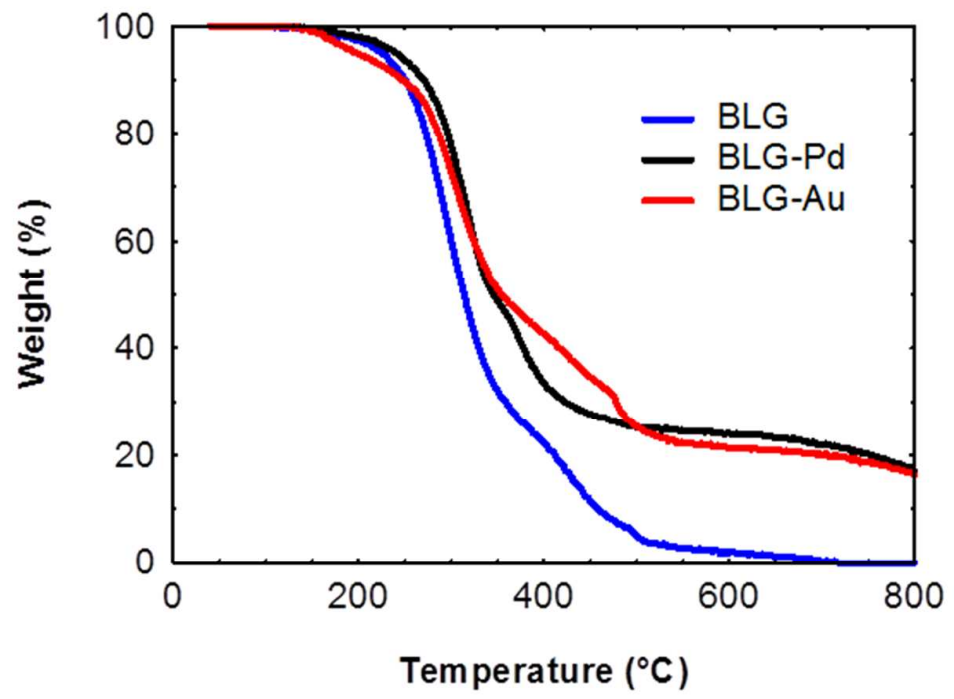

Figure S3. Thermo gravimetric analysis of the amyloid fibrils with and without nanoparticles. The residual weight fractions shown that gold weight fraction is around $18 \%$ and palladium weight fraction is around $19 \%$ were bound to the hybrid protein fibrils.

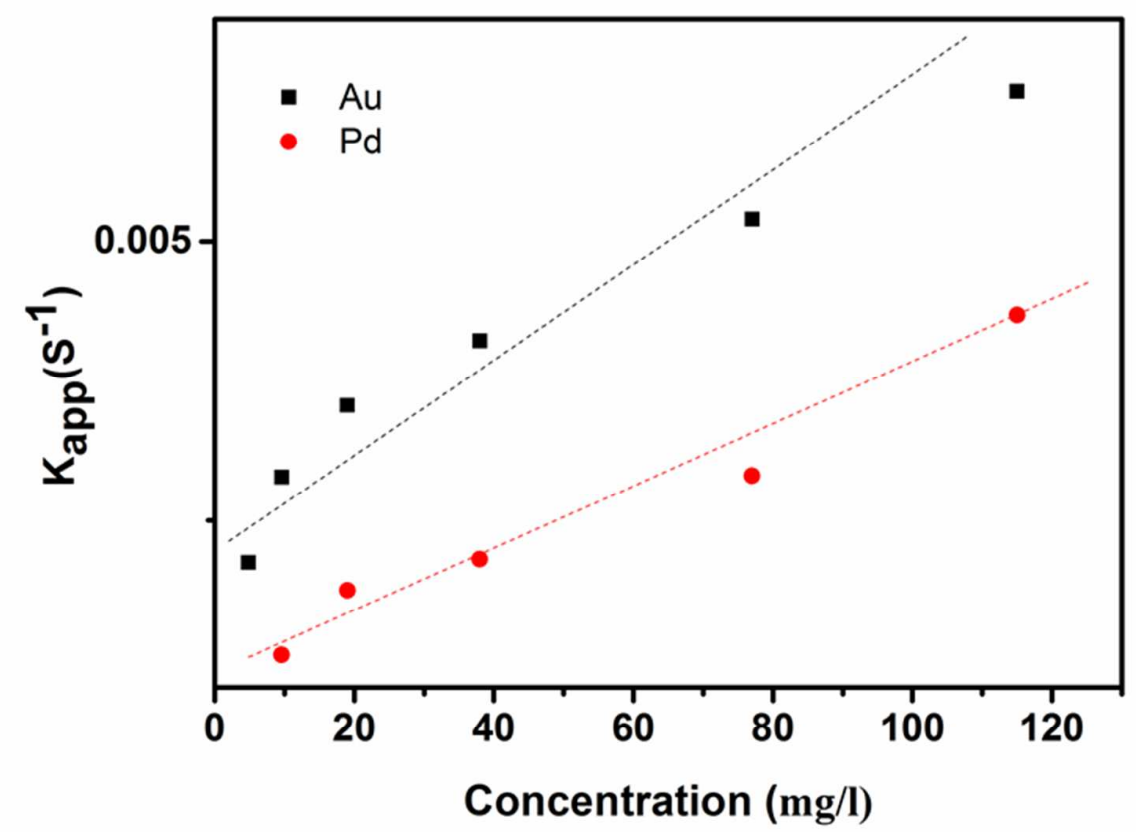

Figure S4. Rate constant $k_{\text {app }}$ versus concentration of $\beta$-lactoglobulin hybrid fibrils (Protein fibrils + nanoparticles). Gold has a higher slope compared to palladium. 

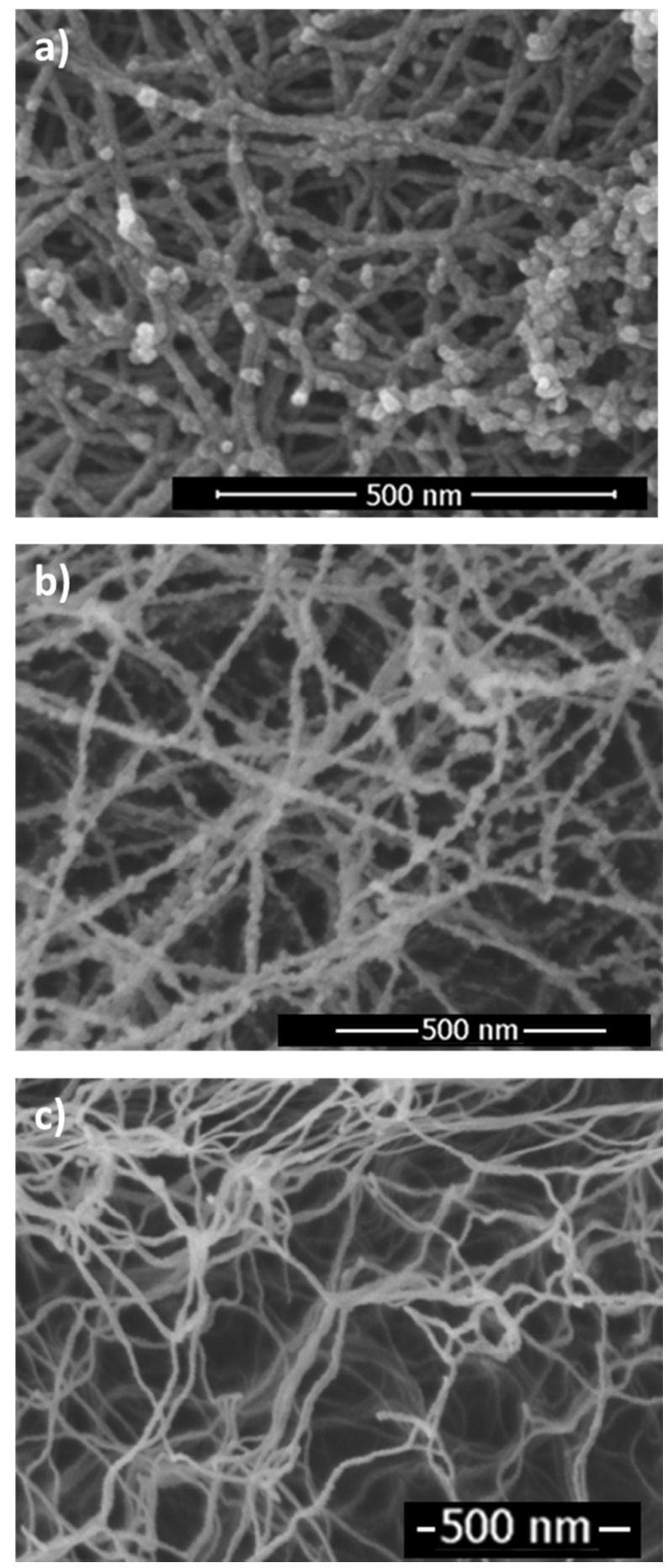

Figure S5. Scanning electron microscopy image of fibrils decorated with and without nanoparticles prepared by solvent exchange to ethanol and supercritical $\mathrm{CO}_{2}$ drying: a) $\beta$ lactoglobulin-gold and b) $\beta$-lactoglobulin-palladium hybrids, where the fibrils are visible with the metal particles attached on their surface. c) bare $\beta$-lactoglobulin fibrils. 


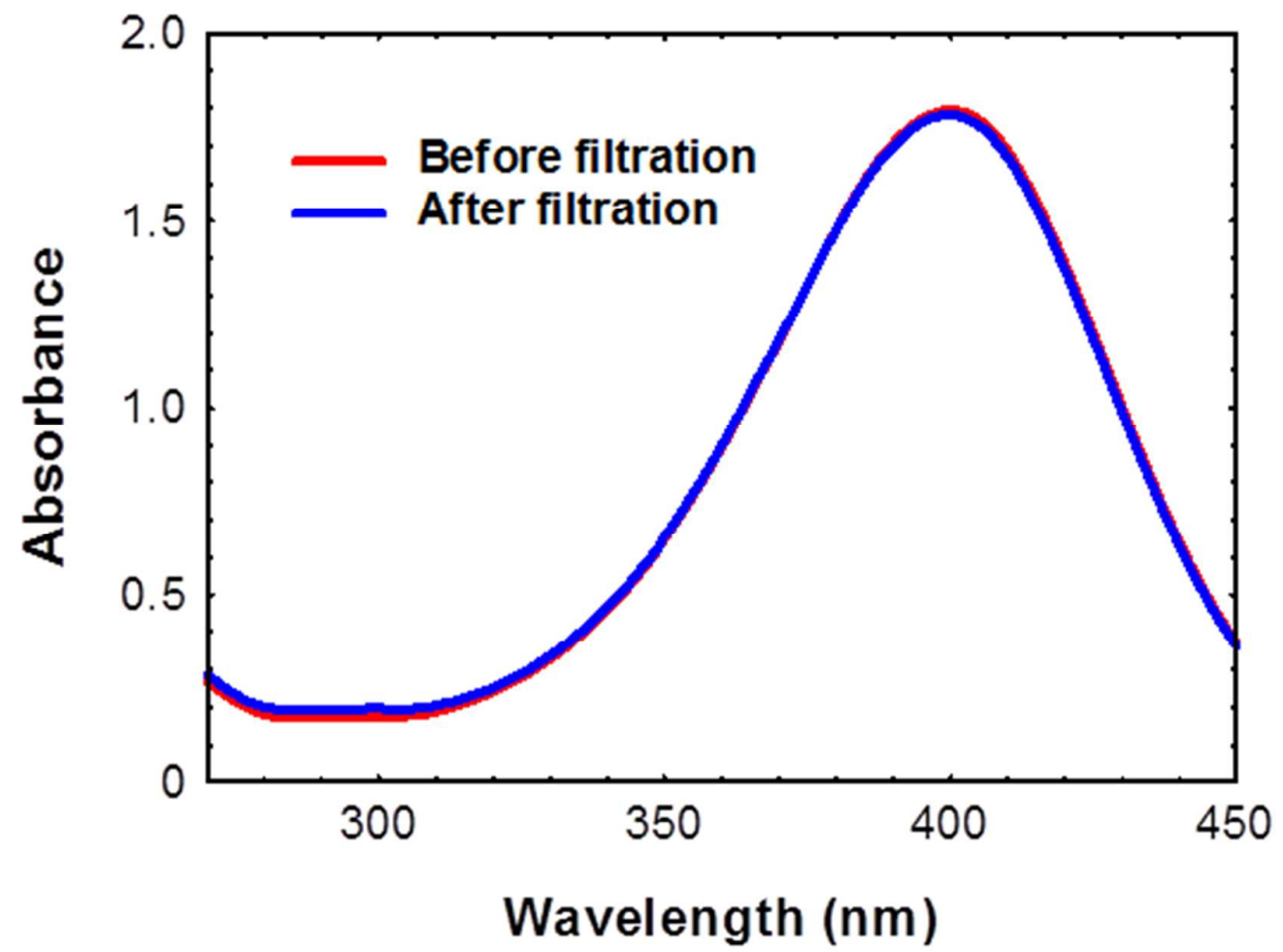

Figure S6. Filtration through the $\beta$-lactoglobulin filter membrane without embedded nanoparticles. UV-Vis spectra before and after filtration do not show any catalytic conversion of 4-nitrophenol to 4-aminophenol. 